\title{
Phylogeny of the African ball-rolling dung beetle genus Epirinus Reiche (Coleoptera: Scarabaeidae: Scarabaeinae)
}

\author{
S. Mlambo, ${ }^{A, B}$ C. L. Sole ${ }^{A}$ and C. H. Scholtz ${ }^{A}$ \\ ${ }^{\mathrm{A}}$ Department of Zoology and Entomology, University of Pretoria, Pretoria 0002, South Africa. \\ ${ }^{\mathrm{B}}$ Corresponding author. Email: smlambo@zoology.up.ac.za
}

\begin{abstract}
Recent phylogenetic analyses have pointed to the dung beetle genus Epirinus as the putative African ancestral roller group. Consequently, we tested the roller status of species in the genus with observational studies and constructed a molecular phylogeny based on partial sequences of two mitochondrial and two nuclear genes for 16 of 29 species. Tested species were confirmed to be dung rollers. Monophyly of the genus was confirmed, lending support to the synonymy of the wingless genus Endroedyantus with Epirinus. Moreover, the phylogenetic hypothesis was found to have a similar topology with a previously published one based on morphological data. A combined molecular/morphology analysis showed congruence between the molecular and morphological datasets. The loss of flight in some species and estimated divergence dates within Epirinus are discussed.
\end{abstract}

\section{Introduction}

The subfamily Scarabaeinae is the largest and most important group of dung insects. They have a worldwide distribution and the approximately 6000 described species are grouped into 334 genera (Scholtz et al. 2009). Scarabs are well-studied because evolutionary biologists have long been fascinated by their complex behaviours (Fabre 1918), unusual morphology and interesting biology (Halffter and Matthews 1966), but also because of their role in maintaining ecosystem functionality and as biodiversity indicators (Davis et. al. 2004; Nichols et al. 2008). Members of the subfamily occur across different biogeographic regions (Scholtz et al. 2009) in a wide range of habitats ranging from forests, grasslands and mountains to deserts. The Afrotropical region 
represents the richest in dung beetle diversity with more than 2000 species (Scholtz et al. 2009) of which $c a 780$ are found in southern Africa (Davis et al. 2008).

Food relocation behaviour has traditionally been used to classify dung beetles. "Tunnellers" bury dung beneath the dung source while "rollers" form a piece of the dung into a ball, which they roll away and bury at some distance from the dung source. Although the global Scarabaeinae dung beetle fauna is divided into 12 tribes (Hanski and Cambefort 1991), some of these divisions lack phylogenetic support (Medina et al. 2003; Philips et al. 2004; Monaghan et al. 2007; Davis et al. 2008; Sole and Scholtz 2010). The current classification is considered to be based on two large 'monophyletic' groups (Cambefort 1991): 1), one containing six tribes of "tunnellers" with Dichotomiini being basal; and 2), the other consisting of six tribes of "rollers" with Canthonini as the basal tribe. The two basal tribes are thought to be of Gondwana origin and that the distribution of the modern representatives reflects this ancient ancestry. However, the phylogenetic relationships within and among them are poorly resolved.

The differentiation between dung beetles that roll and those that tunnel has been the focus of several recent phylogenetic studies in an attempt to explain their evolutionary history, and some have revealed that rollers and tunnellers are phylogenetically mixed and that the relationships within the groups are not as simple and clear-cut as previously thought. Philips et al. (2004) used 200 morphological characters in their analysis which included representative genera from all 12 tribes and concluded that the ancestral Scarabaeinae was a tunneller and that rolling has evolved independently a number of times. Monaghan et al. (2007) performed an extensive molecular phylogenetic analysis and came to several of the same general conclusions as those of Philips et al. (2004). One of these was that the basal extant dung beetle groups are African genera currently placed in the Canthonini and Dichotomiini. Sole and Scholtz (2010) analysed several gene regions of most of the African genera in these two tribes and confirmed that they are, indeed, polyphyletic and that none of the most basal groups actually rolls. The Sole and Scholtz (2010) study left the canthonine genus Epirinus, which was considered to be a genus of "rollers" in previous studies, although this was untested, as the most basal rolling dung beetle group of the African genera. In view of the fact that all of the basal "rollers" have now been shown to not roll (Sole and Scholtz 2010) and that Epirinus is apparently the most basal African roller, it warranted further study. 
Average body length of Epirinus species ranges from approximately $2.5 \mathrm{~mm}$ to $12.0 \mathrm{~mm}$. The larger species are known to roll balls from the herbivore dung with which they are associated. Some of the smallest species had only been collected on carrion and in leaf litter and were therefore thought not to exhibit this behaviour (Scholtz and Howden 1987). For "rollers" to be able to form and roll dung balls away from the dung pat, the dung must be malleable. This is facilitated by the high percentage of water in fresh herbivore dung (Holter and Scholtz, 2005). In their studies of the canthonines and some of the food choice restrictions faced by rollers, Scholtz et al. (2009) suggested that in addition to malleability of the food, body size could also be a constraint on the ability to form and roll balls, with beetles smaller than about $7.0-8.0 \mathrm{~mm}$ possibly incapable of rolling. To date most species of Epirinus recorded as exhibiting ball rolling behaviour have a body length longer than about $8.0 \mathrm{~mm}$. With species both smaller and larger than this within the genus, representatives of Epirinus are suitable candidates for testing the hypothesis that size may be a constraint to making and rolling dung balls. This is of particular interest because of the genus' position as the basal roller among the African genera of the subfamily Scarabaeinae.

In addition to considerable size variation members of the genus Epirinus vary in the presence or absence of wings and in their perceived ability to roll since very small species have been considered physically incapable of forming and rolling balls (Scholtz et al. 2009). In view of some of these differences Epirinus was previously separated into two genera, Endroedyantus Cambefort and Epirinus Reiche, based on the morphological differences associated with the presence or absence of wings. Endroedyantus, representing the flightless group/genus, was synonymised with Epirinus by Scholtz and Howden (1987) in their revision of the genus. The flightless species have also subsequently been shown to comprise two distantly related lineages within the group (Medina and Scholtz 2005) indicating at least two flight loss events. To date Epirinus comprises 29 described and some undescribed species making it by far the largest group of relictual "canthonines" in Africa. All Epirinus species are restricted to southern Africa (Scholtz and Howden 1987; Medina and Scholtz 2005). Of the described species, 10 are wingless. Winged and wingless species, E. bentoi and E. silvestris respectively, are shown in Figure 1. The wingless species are distributed mainly in isolated forest patches along the southeast or northeast coastal regions of southern Africa while the winged species are more widespread in habitats which include inland open grassland and the Nama-Karoo biome. 


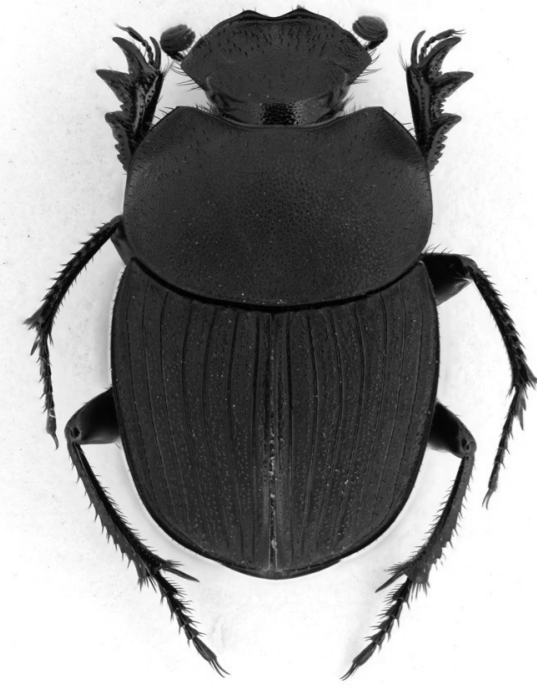

Epirinus bentoi

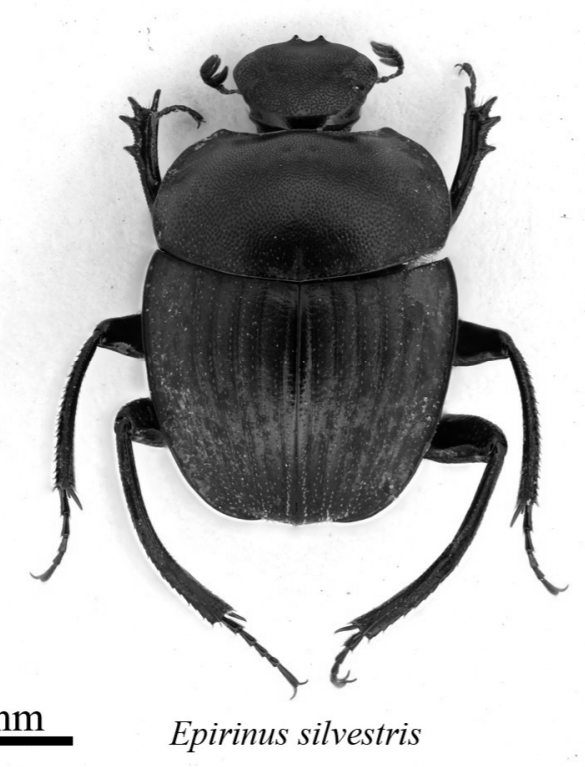

Epirinus silvestris

Figure 1. Photograph showing some superficial morphological differences between winged (Epirinus bentoi) and wingless (E. silvestris) species. 
Consequently, Epirinus is a good model group to test for relatedness among winged and flightless species and to answer questions relating to the effects of flight loss on speciation; and whether small size is a constraint on the ability to roll. In this study we used partial gene sequences from two nuclear and two mitochondrial genes for a molecular analysis of relationships amongst sixteen Epirinus species as well as an analysis combining molecular and morphological data. From these we aimed to compare the result of the combined analysis with the morphology-based hypothesis of Epirinus phylogenetics by Medina and Scholtz (2005). This would provide for a better understanding of the evolutionary trends relating to flightlessness within the genus and together with the observations of food relocation behaviour of the smaller species within the genus, confirm them as true rollers. Lastly speciation and biogeography of Epirinus in southern Africa are discussed.

\section{Materials and Methods}

Sampling for observation of food relocation behaviour

Dung beetles were trapped in localities where the target beetles (body length less than $7.0 \mathrm{~mm}$ ) are known to occur. Live beetles were trapped in standard baited pitfall traps. Cow and pig dung were used for bait. Species collected were E. scrobiculatus $(6.8 \mathrm{~mm})$, E. aeneus $(5.9 \mathrm{~mm})$, E. comosus $(5.2 \mathrm{~mm})$, E. convexus $(4.0 \mathrm{~mm})$, E. ngomae $(3.7 \mathrm{~mm})$ and E. hluhluwensis $(3.3 \mathrm{~mm})$. Body length was calculated as the average of the maximum length listed in the literature (Scholtz and Howden 1987; Medina and Scholtz 2005). The first three species are found mostly in the Fynbos, a habitat of mixed scrub with broken canopy, whereas the remaining three species occur in dense wet forest (Scholtz and Howden 1987; Medina and Scholtz 2005). Little is known about the dung preference among these species.

At least five individuals per species were placed in each of at least two observation chambers and provided with cow dung to determine food relocation behaviour. Observations of the behaviour of the dung beetles were made during the day as it is thought that Epirinus species have diurnal activity patterns (Davis et al. 2008). 


\section{Taxa for phylogenetic study}

Sixteen of the 29 described species of Epirinus were included in this phylogenetic study including representatives from each of the four major groupings obtained in the morphological phylogeny (Medina and Scholtz 2005). Three members of the Canthonini, Circellium bacchus, Gyronotus pumilis and Anacalchos convexus were used as out-group representatives as used by Medina and Scholtz (2005) for direct comparison between the molecular and morphological data. However, the phylogenetic study of the Canthonini and Dichotomiini by Sole and Scholtz (2010) places them in derived positions relative to Epirinus, therefore Namakwanus davisi and Dicranocara deschodti were added as out-groups as they appeared to be sister and basal to the genus. The new out-group species were used in all analyses that were not used for direct comparison with the morphological data. Details of the individuals and species used are presented in Table 1.

\section{DNA extraction and sequencing}

Four gene regions were used for the phylogenetic reconstruction of Epirinus. Sequence data were generated from two mitochondrial genes - cytochrome oxidase I (COI) and 16S ribosomal RNA (16S rRNA) - a portion of the nuclear rRNA large subunit - 28S (28S rRNA) domain 2 - and the CPSase region of Carbamoyl-phosphate synthetase-aspartate transcarbamoylase-dihydroorotase (CAD). These gene regions were chosen as they have been shown in previous studies to be phylogenetically informative in the Coleoptera and other insect groups (Sole et al. 2005; Forgie et al. 2006; Orsini et al. 2007; Monaghan et al. 2007; Wahlberg and Wheat 2008; Wild and Maddison 2008; Sole and Scholtz 2010). Muscle tissue from the metathoracic femur was used

for extraction from at least three individuals per species wherever possible, using the Roche High Pure PCR Template Preparation Kit (Roche, Penzberg, Germany). Primers used for the gene regions are shown in Table 2. For COI, $16 \mathrm{~S}$ and $28 \mathrm{~S}$ domain 2, polymerase chain reactions (PCR) were performed in a final volume of $50 \mu$ l containing $1 \mathrm{x}$ buffer, $25 \mathrm{mM} \mathrm{MgCl}_{2}, 10 \mathrm{~mm}$ DNTP's, 20pmol of each primer and 1U of Super-Therm® DNA polymerase (Southern Cross Biotechnology). Thermal cycling conditions were as follows: $\mathrm{CO} 1$ - denaturing at $94^{\circ} \mathrm{C}$ for 90 seconds, followed by 35 cycles of $94^{\circ} \mathrm{C}$ for 22 seconds, primer annealing at $48-52^{\circ} \mathrm{C}$ for 30 seconds and elongation at $72^{\circ} \mathrm{C}$ for 90 seconds, followed by a final elongation at $72^{\circ} \mathrm{C}$ for 60 seconds; $16 \mathrm{~S}$ - initial denaturation at $94^{\circ} \mathrm{C}$ for 90 seconds, followed by 35 cycles of $94^{\circ} \mathrm{C}$ for 60 
Table 1. Epirinus in-group and the out-group (OG) species sequenced for the study. - indicates PCR amplification failed, * indicates specimens used in the combined data analysis.

\begin{tabular}{|c|c|c|c|c|c|c|c|c|}
\hline \multirow{2}{*}{ Name } & \multirow{2}{*}{$\begin{array}{l}\text { Size } \\
(\mathrm{mm})\end{array}$} & & \multirow{2}{*}{ Locality } & \multirow{2}{*}{ Specimen ID } & \multicolumn{4}{|c|}{ GenBank accession numbers } \\
\hline & & & & & COI & $16 S$ & $28 S$ & CAD \\
\hline \multirow[t]{3}{*}{ Epirinus aeneus } & 5.6 & winged & Darling & EADAR01* & - & GQ289727 & GQ289866 & GQ289935 \\
\hline & & & & EADAR03 & GQ290002 & GQ289728 & GQ289867 & GQ289936 \\
\hline & & & & EADAR04 & GQ290003 & GQ289729 & GQ289868 & GQ289937 \\
\hline \multirow[t]{3}{*}{ E. aquilus } & 3.4 & wingless & Alexandria & EAQA01 & - & HQ289896 & HQ289945 & - \\
\hline & & & Forest & EAQA02 & HQ289974 & HQ289897 & HQ289944 & - \\
\hline & & & & EAQA03* & HQ289975 & HQ289898 & HQ289943 & HQ289923 \\
\hline \multirow[t]{3}{*}{ E. comosus } & 5.2 & winged & Koeggelberg & ECOK01 & HQ289991 & - & - & HQ289924 \\
\hline & & & & ECOK02 & HQ289993 & - & HQ289946 & HQ289925 \\
\hline & & & & ECOK03* & HQ289992 & HQ289899 & HQ289947 & HQ289926 \\
\hline \multirow[t]{4}{*}{ E. convexus } & 4.0 & winged & Dwesa Forest & ECDFT02* & GQ289984 & GQ289704 & GQ289841 & - \\
\hline & & & & ECDFT05 & GQ289985 & GQ289705 & GQ289842 & GQ289924 \\
\hline & & & & ECDFT07 & GQ289986 & GQ289706 & GQ289843 & GQ289925 \\
\hline & & & & ECDFT14 & - & GQ289707 & GQ289844 & - \\
\hline \multirow[t]{3}{*}{ E. flagellatus } & 8.8 & winged & Koeggelberg & EFLK01* & HQ289983 & HQ289903 & HQ289951 & HQ289929 \\
\hline & & & & EFLK02 & HQ290000 & HQ289904 & HQ289952 & - \\
\hline & & & & EFLK03 & HQ290001 & HQ289905 & HQ289953 & HQ289928 \\
\hline E. hluhluwensis & 3.3 & wingless & Hluhluwe & EHLH01 & HQ289995 & HQ289906 & HQ289954 & - \\
\hline
\end{tabular}




\begin{tabular}{|c|c|c|c|c|c|c|c|c|}
\hline & & & & EHLH02* & HQ289996 & HQ289907 & HQ289955 & HQ289930 \\
\hline & & & & EHLH03 & HQ289997 & HQ289908 & HQ289956 & HQ289931 \\
\hline \multirow[t]{2}{*}{ E. minimus } & 2.3 & wingless & Alexandria & EMIA02* & HQ289978 & - & - & - \\
\hline & & & Forest & & & & & \\
\hline \multirow[t]{3}{*}{ E. ngomae } & 3.7 & Wingless & Ngome forest & ENGN01* & HQ289999 & HQ289909 & HQ289957 & HQ289932 \\
\hline & & & & ENGN02 & HQ289987 & HQ289910 & HQ289958 & HQ289933 \\
\hline & & & & ENGN03 & HQ289998 & HQ289911 & HQ289959 & HQ289934 \\
\hline \multirow[t]{3}{*}{ E. obtusus } & 8.0 & Winged & Cradock & EOBC01 & HQ289982 & HQ289912 & HQ289960 & HQ289935 \\
\hline & & & & $\mathrm{EOBC} 02$ & HQ290004 & HQ289913 & HQ289961 & - \\
\hline & & & & EOBC03* & - & HQ289914 & HQ289962 & HQ289936 \\
\hline E. pygidialus & 6.9 & Winged & Utrecht, & EPYU01* & HQ289994 & - & HQ289963 & - \\
\hline E. relictus & 7.8 & winged & Karkloof NR & EREK01* & HQ290003 & HQ289915 & HQ289964 & HQ289937 \\
\hline \multirow[t]{3}{*}{ E. scrobiculatus } & 6.8 & winged & Vanrhynsdorp & ECRV01* & HQ289979 & HQ289900 & HQ289948 & HQ289927 \\
\hline & & & & ECRV02 & HQ289980 & HQ289901 & HQ289949 & - \\
\hline & & & & ECRV03 & HQ289981 & HQ289902 & HQ289950 & - \\
\hline \multirow[t]{3}{*}{ E. sebastiani } & 3.4 & wingless & Alexandria & ESEA01 & HQ289976 & - & HQ289965 & HQ289938 \\
\hline & & & Forest & ESEA02* & HQ290002 & HQ289916 & HQ289966 & HQ289939 \\
\hline & & & & ESEA03 & HQ289977 & HQ289917 & HQ289967 & HQ289940 \\
\hline \multirow[t]{2}{*}{ E. silvestris } & 5.0 & wingless & Outenikwa & EH01* & GQ290019 & GQ289750 & GQ289800 & GQ289946 \\
\hline & & & Pass & EH02 & GQ290020 & GQ289751 & GQ289801 & GQ289947 \\
\hline
\end{tabular}




\begin{tabular}{|c|c|c|c|c|c|c|c|c|}
\hline & & & & ESUL01 & HQ289989 & - & HQ289968 & - \\
\hline \multirow[t]{2}{*}{ E. sulcipennis } & 10.3 & winged & Lesotho & ESUL02* & HQ289990 & HQ289918 & HQ289969 & HQ289941 \\
\hline & & & & ESUL03 & HQ289988 & HQ289919 & HQ289970 & HQ289942 \\
\hline \multirow[t]{3}{*}{ E. validus } & 11.8 & winged & Grahamstown & EVDG01* & HQ289985 & HQ289920 & HQ289971 & - \\
\hline & & & & EVDG02 & HQ289986 & HQ289921 & HQ289972 & - \\
\hline & & & & EVDG03 & HQ289984 & HQ289922 & HQ289973 & - \\
\hline Anachalcos & 23.8 & winged & Island Blue & ACIB01* & GQ289996 & GQ289717 & GQ289768 & GQ289929 \\
\hline convexus (OG) & & & & ACIB02 & GQ289997 & GQ289718 & GQ289769 & - \\
\hline Circellium & 37.3 & wingless & Addo & $\mathrm{C} 1 *$ & GQ290011 & GQ289737 & - & - \\
\hline bacchus (OG) & & & Elephant Park & $\mathrm{C} 3$ & GQ290012 & GQ289738 & GQ289876 & GQ289942 \\
\hline Dicranocara & 10.5 & wingless & Boom River & $\mathrm{DC} 01^{*}$ & GQ290014 & GQ289740 & GQ289793 & GQ289944 \\
\hline deschodti (OG) & & & & DC02 & GQ290015 & GQ289741 & GQ289794 & GQ289945 \\
\hline Gyronotus & 12.6 & wingless & Bosbok & BSGP01* & GQ289993 & GQ289714 & GQ289765 & GQ289950 \\
\hline pumilis_(OG) & & & Strand & BSGP02 & GQ289994 & GQ289715 & GQ289766 & GQ289951 \\
\hline Namakwanus & 8.0 & wingless & Hardap Dam & NHD01* & GQ290021 & GQ289745 & GQ289802 & GQ289955 \\
\hline davisi (OG) & & & & NHD02 & GQ290022 & GQ289746 & GQ289803 & GQ289956 \\
\hline
\end{tabular}


Table 2. Primers used for PCR amplification

\begin{tabular}{lll}
\hline Locus & Primer name and sequence & Reference \\
\hline Cytochrome oxidase 1 & C1-J-2183 (5'CAACATTTATTTTGATTTTTTGG 3') & Simon et al. (1994) \\
& TL2-N-3014 (TCCAATGCACTAATCTGCCATATTA 3') & Simon et al. (1994) \\
16S rRNA & 16Sb2 (5' TTTAATCCAACATCGAGG 3') & Vogler, et al. (1993) \\
& LR-N-13398 (5' CGCCTGTTTAACAAAAACAT 3' & Simon et al. (1994) \\
28S rRNA domain 2 & D2-3551 (5' CGTGTTGCTTGATAGTGCAGC 3' & Gillespie et al. (2005) \\
& D2-4057 (5' TCAAGACGGGTCCTGAAAGT 3') & Gillespie et al. (2005) \\
& 54F (5' GTNGTNTTYCARACNGGNATGGT 3' & Moulton and Wiegmann (2004) \\
& 680R (5' AANGCRTCNCGNACMACYTCRTAYTC 3') & Moulton and Wiegmann (2004) \\
& 338F (5' ATGAARTAYGGYAATCGTGGHCAYAA 3') & Winterton et al. (2010) \\
& 654R (5' TCYTTCCANCCYTTYARSGATTTRTC 3') & Winterton et al. (2010)
\end{tabular}


seconds, annealing $48-50^{\circ} \mathrm{C}$ for 60 seconds and $72^{\circ} \mathrm{C}$ for 90 seconds with a final elongation at $72^{\circ} \mathrm{C}$ for 3 minutes; 28S domain 2 a three cycle touchdown PCR program was followed: initial denaturation at $96^{\circ} \mathrm{C}$ for 20 seconds, followed by 3 cycles of $\left(15 \mathrm{~s}\right.$ at $96^{\circ} \mathrm{C}, 20 \mathrm{~s}$ at $54-55^{\circ} \mathrm{C}, 1 \mathrm{~min}$ at $\left.72^{\circ} \mathrm{C}\right)$ then 7 cycles $\left(12 \mathrm{~s}\right.$ at $96^{\circ} \mathrm{C}, 18 \mathrm{~s}$ at $53-54^{\circ} \mathrm{C}, 55 \mathrm{~s}$ at $\left.72^{\circ \mathrm{C}}\right)$ and 30 cycles $\left(12 \mathrm{~s}\right.$ at $96^{\circ} \mathrm{C}, 15 \mathrm{~s}$ at $52-53^{\circ} \mathrm{C}, 50 \mathrm{~s}$ at $72^{\circ} \mathrm{C}$ ) with a final extension of 1 minute at $72^{\circ} \mathrm{C}$.

The amplification of the desired CAD fragment was a two-step process. Thermal cycling was performed in a final volume of $25 \mu$ l containing $1 \mathrm{x}$ buffer, $25 \mathrm{mM} \mathrm{MgCl}_{2} 10 \mathrm{~mm}$ dNTP's, 10 pmol of each primer and $0.15 \mathrm{U}$ of SuperTherm ${ }^{\circledR}$ polymerase. Dimethyl sulphoxide (DMSO) was added to both amplification steps to improve the sensitivity of the reaction. For the first amplification step primers $54 \mathrm{~F}$ and $680 \mathrm{R}$ were used in a three-cycle touchdown PCR: initial denaturation at $94^{\circ} \mathrm{C}$ for 4 minutes followed by 4 cycles $\left(30 \mathrm{~s}\right.$ at $94^{\circ} \mathrm{C}, 30 \mathrm{~s}$ at $51^{\circ} \mathrm{C}, 2 \mathrm{~min}$ at $\left.72^{\circ} \mathrm{C}\right), 6$ cycles $\left(30 \mathrm{~s}\right.$ at $94^{\circ} \mathrm{C}, 1 \mathrm{~min}$ at $47^{\circ} \mathrm{C}, 1 \mathrm{~min}$ at $72^{\circ} \mathrm{C}$ and 36 cycles $\left(30 \mathrm{~s}\right.$ at $94^{\circ} \mathrm{C}, 20 \mathrm{~s}$ at $42^{\circ} \mathrm{C}, 2 \frac{1}{2} \mathrm{~min}$ at $72^{\circ} \mathrm{C}$ ) and a final extension of $3 \mathrm{~min}$ at $72^{\circ} \mathrm{C}$. Touchdown PCR is useful for improving the specificity, sensitivity and yield of PCR amplification (Korbie and Mattick 2008) particularly for templates that are difficult to amplify such as CAD. The gradual lowering of temperature to the calculated annealing temperature during cycling favours amplification of the desired product. In the second amplification step $1 \mu 1$ of the resulting amplified product was used in the same reaction mixture except at a $1.5 \mathrm{mM} \mathrm{MgCl}_{2}$ concentration using internal primers $338 \mathrm{~F}$ and 654R under the following conditions: initial denaturation for $4 \mathrm{~min}$ at $94^{\circ} \mathrm{C}$ followed by 4 cycles $\left(30 \mathrm{~s}\right.$ at $94^{\circ} \mathrm{C}, 30 \mathrm{~s}$ at $51^{\circ} \mathrm{C}, 80 \mathrm{~s}$ at $\left.72^{\circ} \mathrm{C}\right)$, then 36 cycles $\left(30 \mathrm{~s}\right.$ at $94^{\circ} \mathrm{C}, 30 \mathrm{~s}$ at $45^{\circ} \mathrm{C}, 80 \mathrm{~s}$ at $72^{\circ} \mathrm{C}$ ) and a final extension of $3 \mathrm{~min}$ at $72^{\circ} \mathrm{C}$ in a Geneamp ${ }^{\circledR}$ PCR System 9700 (Applied Biosystems). Forward and reverse strands were sequenced using the amplification primers and BigDye v.3.1 (ABI).

\section{Phylogenetic analysis and dating}

The sequences were viewed in Chromas version 2.0, assembled and edited in CLC Bio Main Workbench 5 (http://www.clcbio.com), and subsequently aligned in MAFFT version 6 (Katoh and Toh 2008). Thereafter the sequences were adjusted manually. The phylogenetic relationships among Epirinus sequences were inferred using maximum parsimony (MP) and maximum likelihood (ML) analyses implemented in PAUP*4.010b (Swofford 2003) while MrBayes version 3.1.2 (Ronquist and Huelsenbeck 2003) was used to infer a Bayesian phylogram. 
Phylogenetic trees were generated for individual and combined gene regions. For the Parsimony analysis all characters were equally weighted and unordered and tree statistics calculated excluding uninformative sites. Heuristic searches with 10 random addition sequences were used for each of 1000 bootstrap replicates. Partitioned Bremer Support (PBS) (Baker et al. 1998) and Partition Congruence Indices (PCI) (Brower 2006) implemented in PAUP* were applied using TreeRot version 3 (Sorenson and Franzosa 2007) to test whether these DNA sequences are congruent with the morphological data set analysed elsewhere (Medina and Scholtz 2005). Conflict between the molecular and morphological data was identified and the relative contributions of the different data sets to the phylogenetic tree were determined. When there is no conflict between partitions PCI and PBS values are equal and as conflict increases, PCI values decrease until they become negative (Brower 2006).

Maximum likelihood analyses employed MrModeltest version 3.7 (Nylander, 2004) (Table 3) to determine the model of sequence evolution which best fit the DNA data. Parameters from MrModelTest were used in a heuristic search and nodal support was estimated using 1000 bootstrap replications. Bayesian analysis allows the data to be partitioned and optimal models of nucleotide substitution applied to each partition. The model of nucleotide substitution for each gene region was assessed using the Akaike Information Criteria (AIC) in MrModeltest version 3.7 (Nylander 2004) (Table 3). In both molecular and combined molecular and morphological data analyses 5 million generations were run with 3 cold and one heated chain with trees sampled every 100 generations. Posterior probabilities were calculated after discarding the initial $20 \%$ as burn-in. Two independent runs were performed for each analysis.

There are many approaches to molecular dating. To estimate divergence times of the different lineages within Epirinus we chose a method that corrects for evolutionary rate heterogeneity among gene regions (Rutschmann 2006). The program Beast version 1.4.8 (Drummond and Rambaut 2007), which uses MCMC estimation, was used to estimate lineage ages. Cytochrome Oxidase I data for all the individuals successfully sequenced were used. The published rates of evolution of 0.0075 and 0.012 mutation changes per million years were used to cover the range of rates reported (Brower 1994; Juan et al. 1995; Farrell 2001; Smith and Farrell 2005; Wirta et al. 2008; Sole and Scholtz 2010). Lineage age was estimated under the log normal uncorrected model assuming the Yule speciation for all estimates using the GTR $+\mathrm{I}+\mathrm{G}$ 
Table 3. Estimated model parameters and data characteristics for 16S, COI, $28 \mathrm{~S}$ domain 2, CAD and combined dataset for Epirinus.

\begin{tabular}{|c|c|c|c|c|c|}
\hline & $16 S$ & COI & D2 & CAD & Combined \\
\hline Number of samples & 36 & 38 & 40 & 27 & 16 \\
\hline Aligned positions & 396 & 748 & 591 & 899 & 2639 \\
\hline Parsimony informative sites & 206 & 179 & 142 & 230 & 826 \\
\hline Tree length (MP) & 417 & 528 & 248 & 477 & 2030 \\
\hline Number of trees (MP) & 100 & 100 & 27 & 100 & 1 \\
\hline $\mathrm{CI} / \mathrm{RI}$ & $0.729 / 0.858$ & $0.489 / 0.486$ & $0.802 / 0.867$ & $0.669 / 0.682$ & $0.586 / 0.656$ \\
\hline Best-fit model & $\mathrm{GTR}+\mathrm{G}$ & $\mathrm{GTR}+\mathrm{I}+\mathrm{G}$ & GTR+I & $\mathrm{GTR}+\mathrm{G}$ & $\mathrm{GTR}+\mathrm{I}+\mathrm{G}$ \\
\hline A frequency & 0.3522 & 0.3386 & 0.19 & 0.2929 & 0.2863 \\
\hline C frequency & 0.1313 & 0.123 & 0.3063 & 0.216 & 0.2004 \\
\hline $\mathrm{G}$ frequency & 0.1508 & 0.1268 & 0.3313 & 0.2346 & 0.2128 \\
\hline $\mathrm{T}$ frequency & 0.3656 & 0.4116 & 0.1724 & 0.2565 & 0.3006 \\
\hline Gamma & 0.9625 & 1.1077 & equal & 0.291 & 1.2154 \\
\hline Invariable sites & 0 & 0.4652 & 0.4985 & 0 & 0.3929 \\
\hline
\end{tabular}


model (Table 3). The analyses were run for 170 million generations starting from a random tree and the results were analysed with the programme Tracer version 1.3 (Drummond and Rambaut 2007). The analyses were run twice to validate consistency of the time estimates between runs.

\section{Results}

\section{Food relocation behaviour}

All of the six small Epirinus species collected to test for rolling behavior were observed to roll dung balls in typical scarabaeine fashion for the first time (except E. aeneus reported by Davis et al. (2008)). Both round (food) and pear-shaped (brood) balls were observed for E. ngomae and E. hluhluwensis while Epirinus scrobiculatus rolled irregularly shaped balls.

\section{Molecular phylogenetic analysis}

The complete assembled matrix across four gene regions consisted of 2639 aligned base pairs (bp) from 16 of 29 species. The matrix was made up as follows: COI mtDNA $\approx 748 \mathrm{bp} / 179$ parsimony informative sites $(\mathrm{PI}) ; 16 \mathrm{~S}$ rRNA $\approx 414$ bp/206 PI, 28S D2 rRNA $\approx 628$ bp/142 PI and $\mathrm{CAD} \approx 899 \mathrm{bp} / 230 \mathrm{PI}$. Table 3 shows the other statistics associated with the parsimony analysis. The genus is monophyletic based on all three tree drawing methods (posterior probability $=1.00 ;$ ML bootstrap value $=100 \%$; MP bootstrap value $=95 \%$ ). The three trees were similar in topology and only the Bayesian phylogram is presented (Figure 2) with posterior probabilities, ML and MP bootstrap support. Relationships in the Bayesian and ML analyses were the same, however, overall the Bayesian phylogram was better resolved with moderate to strong support. In the parsimony analysis E. aquilus + E. sebastiani, are sister to the rest of the species in lineage B and E. scrobiculatus, E. aeneus , E. minimus and E.convexus + E. silvestris form a polytomy at the base of the tree. Figure 2 shows lineage A consisting of three species, $E$. silvestris, E. convexus and E. minimus with strong support (0.96 posterior probability) as sister to the rest of the species in the genus. The species E. aeneus and E. scrobiculatus branch off in succession next. Lineage B consists of three groups. B1 includes E. obtusus, E. sulcipennis, E. validus and E. flagellatus (1.00 posterior probability and $99 \% \mathrm{MP}$ bootstrap value) and sister to that are E. comosus and E. pygidialis in lineage B2, (1.00 posterior probability and $90 \% \mathrm{MP}$ 


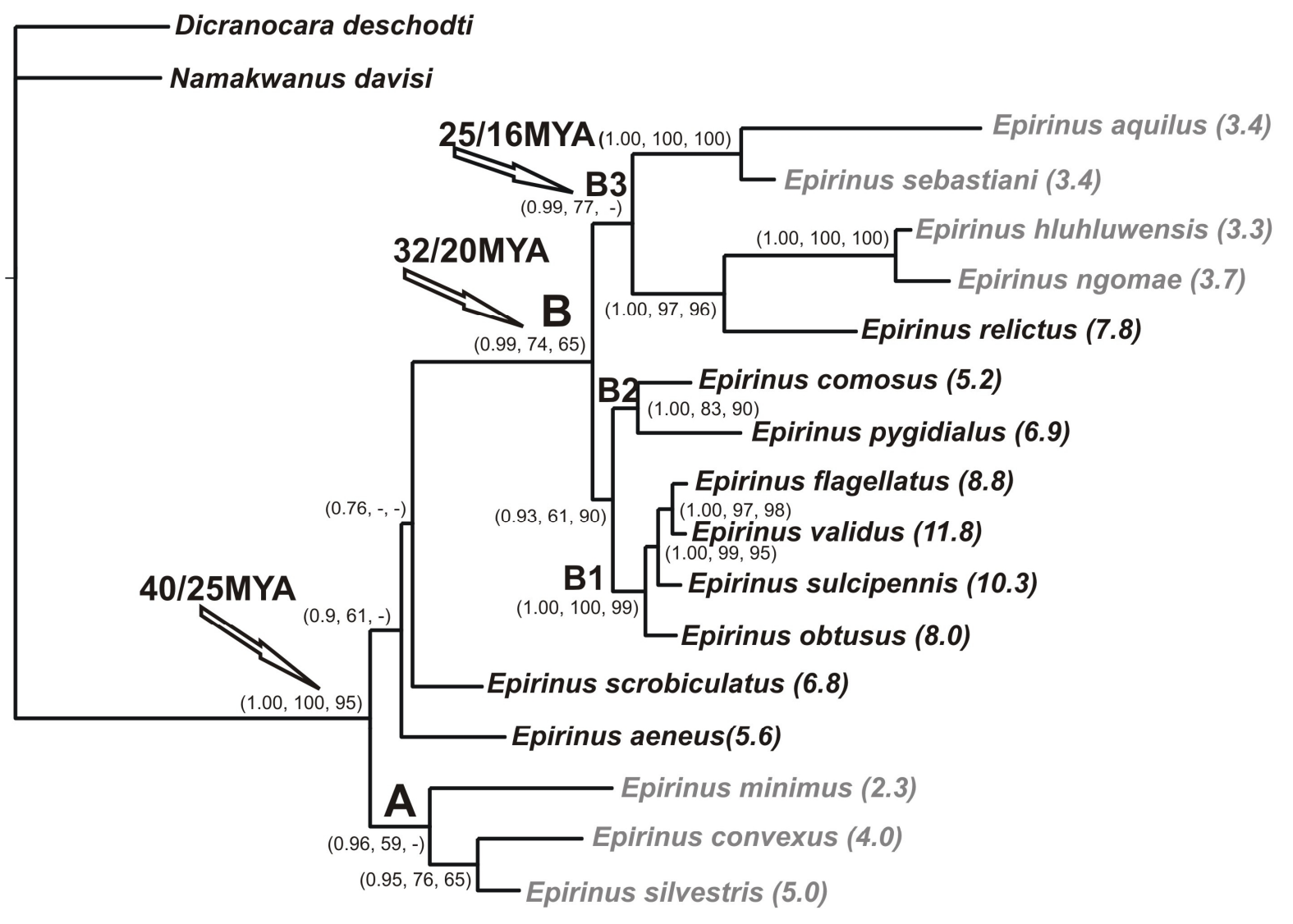

Figure 2. Molecular (16S, COI, D2 and CAD) Bayesian inference phylogram. Posterior probabilities, maximum likelihood and parsimony bootstrap values indicated where $0.5 / 50 \%$ or higher. Divergence times for the flightless lineages are indicated at nodes A, $\mathrm{B}$ and B3. Flightless taxa in grey font. Size in brackets in $\mathrm{mm}$ in front of species name. 
bootstrap value). Lineage $\mathrm{B}_{3}$ with posterior probability 0.99 , includes $E$. relictus sister to the flightless pair E. hluhluwensis and E. ngomae, which all share the same ancestor with the flightless pair E. sebastiani and E. aquilus.

\section{Congruence of molecular and morphological data sets}

\section{Phylogenetic trees}

Phylogenetic relationships within Epirinus were investigated by Medina and Scholtz (2005), shown in Figure 3. Their analysis was based on 79 morphological characters including male and female genitalia. Monophyly of the genus was supported. However, as in other scarabaeines (Philips et al. 2004), there was a high degree of homoplasy in the morphological characters that were used.

The combined molecular and morphological phylogeny Bayesian phylogram (Figure 4) is largely congruent with the morphological species groupings of Medina and Scholtz (2005) (Figure 3) according to both Bayesian and Parsimony analyses. Essentially the species are grouped in the same way except that in the molecular phylogeny E. aquilus and E. sebastiani (Figure 2) are placed among the more derived group of flightless species whereas the morphological data places them in the basal clade of flightless Epirinus. The molecular tree is more reliable for this clade (B3) as the morphological E. sebastiani (E. aquilus (E. convexus + E. minimus)) clade is poorly supported without a single unique character supporting it.

\section{Bremer Support}

An assessment of the relative contribution of each data partition of the combined tree indicated that most conflicts were from the nuclear gene partitions CAD and D2. Three of the 15 nodes in the parsimony phylogram had negative PCI values indicating strong incongruence between the data sets (Table 4; Figure 5). For nodes 2 and 4, D2 contained the most nodal conflict while for node 8 it was COI. Lending the most support to the nodes was COI (14) dataset followed by $16 \mathrm{~S}$ (10) and thereafter the morphological data contributed to eight nodes. 


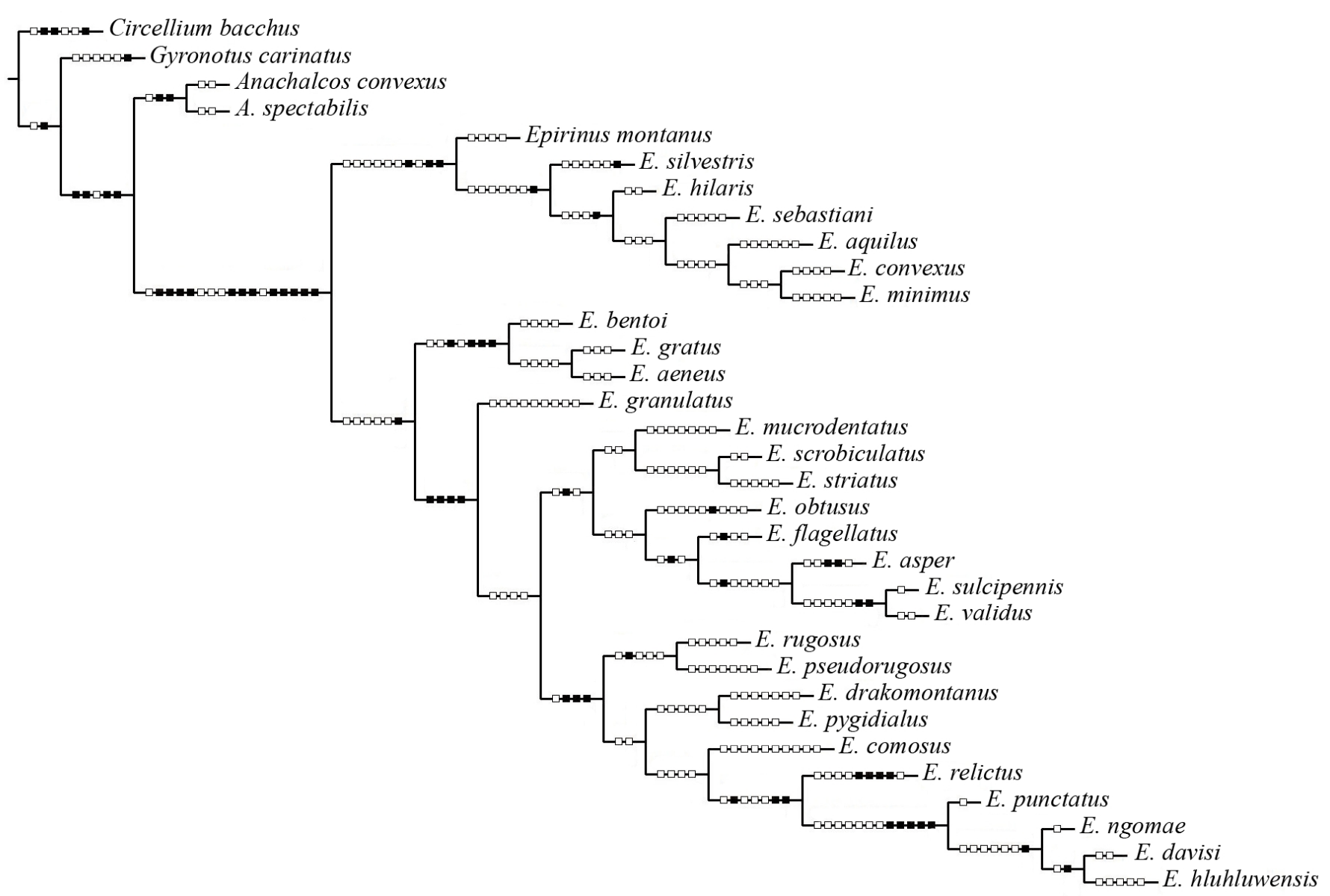

Figure 3. Strict consensus tree from 3 cladograms (331 steps, CI $=40, \mathrm{RI}=67$ ) based on morphological characters. Black hatch marks indicate changes without homoplasy and white hatchmarks indicate changes with homoplasy. Reproduced from Medina and Scholtz (2005). 


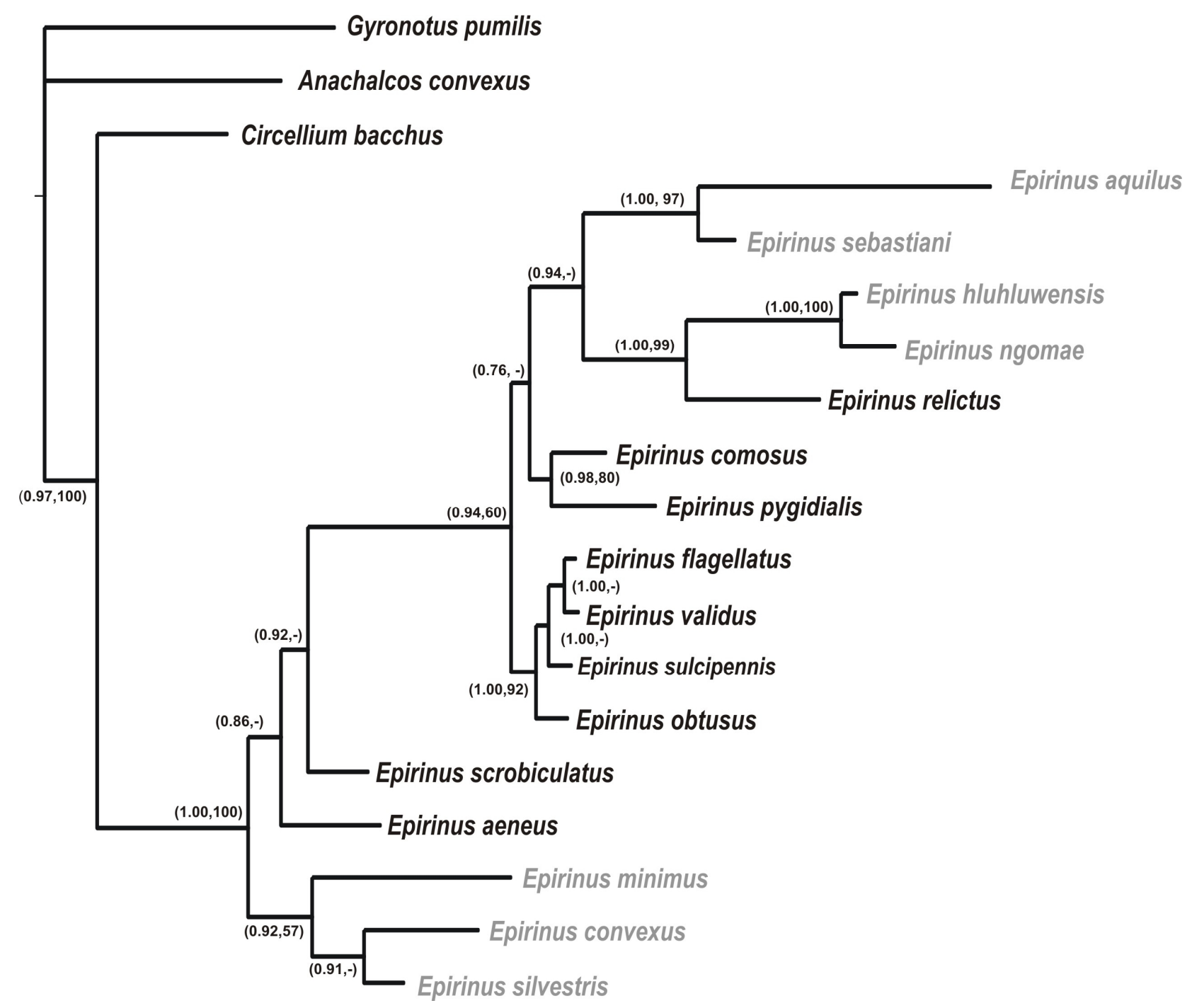

Figure 4. Combined morphological and molecular Bayesian inference phylogram with posterior probabilities and parsimony bootstrap values respectively where $0.5 / 50 \%$ or higher. Flightless taxa - grey font. 
Table 4. Bremer support indices calculated from the parsimony analysis. Node numbers correspond to those on the parsimony phylogram (Fig. 5)

\begin{tabular}{|c|c|c|c|c|c|c|c|}
\hline \multirow[t]{2}{*}{ Node } & \multirow[t]{2}{*}{ Bremer } & \multirow[t]{2}{*}{ PCI } & \multicolumn{5}{|l|}{ PBS values } \\
\hline & & & $\mathrm{D} 2$ & $\mathrm{COI}$ & $16 \mathrm{~S}$ & CAD & morphology \\
\hline 1 & 16 & 19.5 & -2.5 & 1 & 4 & -1 & 14.5 \\
\hline 2 & 0.3 & -21.3 & -2.5 & 0 & 4 & -1 & -0.5 \\
\hline 3 & 0 & 0 & 2.5 & 0 & 4 & -1 & -0.5 \\
\hline 4 & 2 & -1.5 & -3.5 & 0 & 7 & -4 & 2.5 \\
\hline 5 & 0 & 0 & -2.5 & 0 & 4 & -1 & -0.5 \\
\hline 6 & 103.5 & 107.5 & 43 & 21 & 9 & 27 & 3.5 \\
\hline 7 & 11 & 14.3 & -2.5 & 4 & 4 & -1 & 6.5 \\
\hline 8 & 2 & -3 & 0 & -7 & -2 & 0 & 11 \\
\hline 9 & 8 & 11.8 & 0 & 0 & -1 & 3 & 6 \\
\hline 10 & 7 & 9.7 & 3.5 & 7 & -4 & 1 & -0.5 \\
\hline 11 & 4 & 4.8 & 2.5 & 7 & -4 & 1 & -2.5 \\
\hline 12 & 6 & 6.3 & -3.5 & 2 & 14 & -8 & 1.5 \\
\hline 13 & 0 & 0 & -2.5 & 0 & 4 & -1 & -0.5 \\
\hline 14 & 20 & 22.9 & 4.5 & 22 & -12 & 1 & 4.5 \\
\hline 15 & 0 & 0 & -2.5 & 0 & 4 & -1 & -0.5 \\
\hline
\end{tabular}




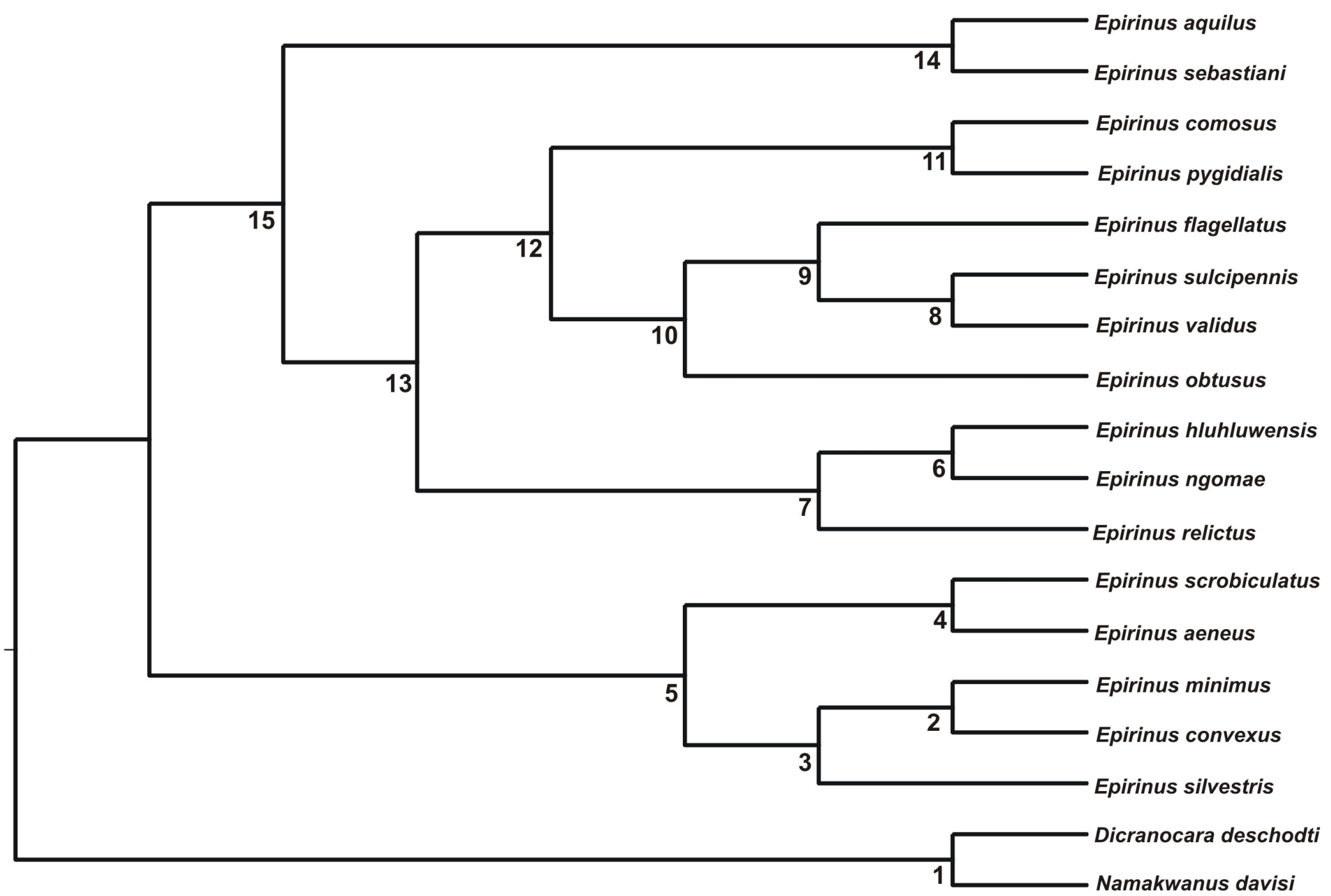

Figure 5. Shortest tree constrained to include nodes obtained in the Bayesian analysis. Node numbers indicated below branches. 


\section{Times of divergence}

Our results indicated that the mean estimate of the earliest split in the genus occurred $40(26 / 56)$ and 25 (16/35) MYA for the rates of 0.0075 and 0.012 substitutions /site/MYA respectively (upper and lower credibility limits in brackets). Lineage B3 which includes possibly the most derived flightless species, appears to have diverged around 26 (16/37) and 16 (10/23) MYA (Fig.3). Our results for Epirinus are consistent with those for other African canthonine genera reported by Sole and Scholtz (2010) with the oldest having diverged from its closest relative in the Eocene epoch 56-34 MYA, and many splits subsequently occurring during the Oligocene and Miocene. In their study of five (out of a possible 13) Madagascan canthonine genera, the oldest have an estimated divergence date in the Miocene (14 MYA) (Orsini et al. 2007). The "roller" tribes Scarabaeini and the Argentine endemic Eucraniini also have a Miocene origin 23-10 MYA (Forgie et al. 2005) and, 16-12 MYA (Ocampo and Hawks, 2006) respectively.

\section{Discussion}

Our research has shown that even the smallest species of Epirinus are rollers; the monophyly of the genus has been confirmed, and the molecular and combined molecular and morphological phylogenetic hypotheses have been shown to be largely congruent with the existing morphological phylogeny. The poor support of E. aquilus and E. sebastiani in the morphological dataset of Medina and Scholtz (2005) has meant that their phylogenetic placement and relationships with sister taxa are better resolved with the gene regions used in this study.

\section{Food relocation}

Recent phylogenetic studies have postulated that in Scarabaeinae rolling balls of dung evolved independently several times (Philips et al. 2004; Monaghan et al. 2007). Sole and Scholtz (2010) tried to "tease apart the different taxa of tunnellers and rollers" concluding that within the African Canthonini and Dichotomiini Epirinus appeared to be the most basal of all rollers. Our assessment of food relocation behaviour confirms that the genus Epirinus appears to be a 'true roller'. It also appears that these species may exhibit plasticity in their food relocation behaviour as seen in other dung beetle taxa (Philips et al. 2004 and references therein). Admittedly, most 
dung beetles show selectivity for particular dung based on qualities such as dropping size, texture and fibre content (Rahagalala et al. 2009) but they may also be opportunists that exhibit different behaviours to suit their environment.

In addition, most of these smaller species are flightless and occur in forests so that locating dung pellets of small animals could potentially be easier for them than locating large herbivore dung pats (Gill 1991). Competition at a large dung pat would also favour large beetles (Scholtz et al. 2009). It must also be pointed out that some species of Epirinus are known to be attracted to bait containing a mixture of dung and carrion, a fact that may lend support to the hypothesis of plasticity concerning food and its relocation.

\section{Phylogeny}

Overall the phylogenetic hypothesis produced for Epirinus is well supported. The genus is monophyletic so there is strong support for the synonymy of the flightless species (Endroedyantus) with Epirinus (Scholtz and Howden 1987). However, broader taxon sampling would possibly give better support for resolution to nodes in lineage B. Lineage A, which appears basal in the phylogeny, consists of three flightless species. This is corroborated by the morphological phylogeny of Medina and Scholtz (2005). The species in lineage B are all winged while all but one species in lineage B3 are flightless. Flightlessness is generally accepted as a derived condition from a flying ancestor. It has evolved independently many times in different Scarabaeoidea groups (Scholtz 2000). In the Scarabaeinae, examples include aptery evolving independently at least three times within Scarabaeini (Harrison and Philips 2003,) and twice in Epactoides (Canthonini) (Wirta and Montreuil 2008).

There appear to be at least two origins of flightlessness in our analysis- a monophyletic group of three species from the basal node and four others in the most derived clade. Both groups are sister to winged species so we can conclude that flightlessness in Epirinus is derived from winged ancestors. Its evolution was likely driven by environmental pressures. According to Scholtz (2000) increased environmental homogeneity is one of the conditions that favour secondary loss of wings. All the flightless species are found in forest habitats which provide stable and persistent microhabitats that promote flightlessness. 
Flightlessness has been suggested as a factor influencing speciation in other dung beetle groups such as the flightless genera of Scarabaeini (Forgie et al. 2005). However, although there is no data to make precise comparisons between speciation rates in winged and flightless lineages, branch lengths of ancestral nodes do not suggest any differences. Although flightlessness appears not to have driven speciation, this adaptation may have promoted endemicity in these species. All the flightless species occur in isolated forest patches along the eastern coast of South Africa

\section{Historical biogeography}

Although our COI phylogeny does not match the combined phylogeny exactly, the winged and wingless species of Epirinus form distinct clades so that we can estimate the divergences of the different groups. Our molecular dating results appear to confirm that dung beetle biogeography mostly reflects evolution since the Miocene to Pleistocene (Cambefort 1991). Many canthonines in Africa appear to be represented by relicts of a once widespread temperate fauna (Deschodt and Scholtz 2008). All the flightless, and a few winged species of Epirinus, are forest relicts found in undisturbed disjunct forest habitats (Davis et al. 2008). According to Eeley et al. (1999) the warmer, wetter conditions characteristic of Pleistocene hyperthermal periods may have caused an expansion of the forest biome whereas cooler drier hypothermal periods would have caused a reduction in the extent of forests. The expansion and contraction would have resulted in fragmentation of the forests and in that way taxa would have been isolated in forest refugia. The rest of the species are found in a range of more open habitats. The winged species are bigger and have probably been able to successfully compete with highly efficient rollers from the tribes Scarabaeini, Gymnopleurini and Sisyphini where they overlap.

\section{Conclusion}

In conclusion, we provide evidence that Epirinus is a monophyletic group, with support for the synonymisation of Endroedyantus with Epirinus and demonstrate that even some of the the smallest species within the genus are rollers. These beetles seem prone to behaviour shifts to suit different environmental conditions for their survival. The hypothesis that body size is a 
constraint on the ability to form and roll balls is thus rejected. Our analysis has also shown that flightlessness evolved twice within Epirinus with environmental pressure the likely cause for this condition.

\section{References}

Baker, R.H., Yu, X., DeSalle, R. (1998). Assessing the relative contribution of molecular and morphological characters in simultaneous analysis trees. Molecular Phylogenetics and Evolution 9, 427-436.

Brower, A.V.Z. (1994). Rapid morphological radiation and convergence among races of the butterfly Heliconius erato inferred from patterns of mitochondrial DNA evolution. Proceedings of the National Academy of Science USA 91, 6491-6495.

Brower, A.V.Z. (2006). The how and why of branch support and partitioned branch support, with a new index to assess partition incongruence. Cladistics 22, 378-386.

Cambefort, Y. (1991). Biogeography and evolution. In 'Dung Beetle Ecology'. (Eds I. Hanski and Y. Cambefort.) pp 51-67. (Princeton University Press: NJ, USA.).

Davis, A.L.V., Scholtz, C.H., Dooley P.W., Bham, N. and Kryger, U. (2004). Scarabaeine dung beetles as indicators of biodiversity, habitat transformation and pest control chemicals in agro-ecosystems. South African Journal of Science 100, 415-424.

Davis, A.L.V., Frolov, A.V. and Scholtz, C.H. (2008). The African dung beetle genera. pp 272. Protea Book House, Pretoria.

Deschodt, C.M. and Scholtz, C.H. (2008). Systematics of South African forest-endemic dung beetles: new genera and species of small Canthonini (Scarabaeidae: Scarabaeinae). African Entomology 16, 91-106.

Drummond, A.J. and Rambaut, A. (2007). Beast: Bayesian Evolutionary Analysis Sampling Trees, BMC. Evolutionary Biology 7, 214. 
Eeley, H.A.C., Lawes, M.J. and Piper, S.E. (1999). The influence of climate change on the distribution of indigenous forest in KwaZulu-Natal, South Africa. Journal of Biogeography 26, 595-617.

Fabre, J. -H. (1918). The Sacred Beetle and Others. Dodd, Mead and Company, NY.

Farrell, B.D., (2001). Evolutionary assembly of the Milkweed Fauna: cytochrome oxidase I and the age of Tetraopes beetles. Molecular Phylogenetics and Evolution 18, 467-478.

Forgie, S. A., Kryger, U., Bloomer, P. and Scholtz, C. H. (2006). Evolutionary relationships among the Scarabaeini (Coleoptera: Scarabaeidae) based on combined molecular and morphological data. Molecular Phylogenetics and Evolution 40, 662-678.

Gill, B.D. (1991). Dung beetles in tropical American forests. In 'Dung Beetle Ecology'. (Eds I. Hanski and Y. Cambefort.) pp 211-229. (Princeton University Press: NJ, USA.)

Gillespie, J.J., Munro, J.B., Heraty, J.M., Yoder, M.J., Owen, A.K. and Carmichael, A.E. (2005). A secondary structural of the 28S rRNA expansion segments D2 and D3 for Chalcidoid Wasps (Hymenoptera: Chalcidoidea). Molecular Biology and Evolution 22, 1593-1608.

Halffter, G. and Matthews, E.G. (1966). The natural history of dung beetles of the Subfamily Scarabaeinae (Coleoptera, Scarabaeidae). Folia Entomologica Mexicana 12-14, 1-312.

Hanski, I. and Cambefort, Y. (1991). Dung Beetle Ecology. pp. 481. Princeton University Press, USA.

Harrison, J. du G. and Philips, T.K. (2003). Phylogeny of Scarabaeus (Pachysoma MacLeay) stat. nov., and related flightless Scarabaeini (Scarabaeidae: Scarabaeinae). Annals of the Transvaal Museum 40, 47-71.

Holter, P. and Scholtz, C.H. (2005). Are ball-rolling (Scarabaeini, Gymnopleurini, Sisyphini) and tunneling scarabaeine dung beetles equally choosy about the size of ingested dung particles? Ecological Entomology 30, 700-705.

Juan, C., Oromi, P., Hewitt, G.M., (1995). Phylogeny of the genus Hegeter (Tenebrionidae, Coleoptera) and its colonization of the Canary Islands deduced from cytochrome oxidase I mitochondrial DNA sequences. Proceedings of the Royal Society of London 261, 173-180. 
Katoh, K. and Toh, H. (2008). Recent developments in the MAFFT multiple sequence alignment program. Briefings in Bioinformatics 9, 286-298.

Korbie, D.J. and Mattick, J.S. (2008). Touchdown PCR for increased specificity and sensitivity in PCR amplification. Nature Protocols 3(9), 1452-1456.

Medina, C.A., Scholtz, C.H. and Gill, B.D. (2003). Morphological variation and systematics of Canthon Hoffmansegg 1817, and related genera in New World Canthonini dung beetles (Coleoptera, Scarabaeinae). Mitteilungen aus dem Museum für Naturkunde Berlin, Deutsche Entomologische Zeitschrift 50, 23-68.

Medina, C.A. and Scholtz, C.H. (2005). Systematics of the southern African genus Epirinus Reiche (Coleoptera: Scarabaeinae: Canthonini): descriptions of new species and phylogeny. Insect Systematics \& Evolution 36, 145-160.

Monaghan, M.T., Inward, D.G., Hunt, T, H. and Vogler, A.P. (2007). A molecular phylogenetic analysis of the Scarabaeinae (dung beetles). Molecular Phylogenetics and Evolution 45, 674-692.

Moulton, J.K. and Wiegmann, B.M. (2004). Evolution and phylogenetic utility of CAD (rudimentary) among Mesozoic-aged eremoneuran Diptera (Insecta). Molecular Phylogenetics and Evolution 31, 363-378.

Nichols, E., Spector, S., Louzada, J., Larsen, T., Amezquita, S. and M.E. (2008). Ecological functions and ecosystem services provided by Scarabaeinae dung beetles. Biological Conservation 141, 1461-1474.

Nylander, J.A.A. (2004). MrModeltest. Program distributed by the author. (Evolutionary Biology Centre, Uppsala University), Version 2.2.

Ocampo, F.C. and Hawks, D.C. (2006). Molecular phylogenetics and evolution of the food relocation behaviour of the dung beetle tribe Eucraniini (Coleoptera: Scarabaeidae: Scarabaeinae). Invertebrate Systematics 20, 557-570.

Orsini, L., Koivulehto, H. and Hanski, I. (2007). Molecular evolution and radiation of dung beetles in Madagascar. Cladistics 23, 145-168. 
Philips, K.T., Pretorius, E. and Scholtz, C.H. (2004). A Phylogenetic analysis of dung beetles (Scarabaeinae : Scarabaeidae): unrolling an evolutionary history. Invertebrate Systematics 18, 53-88.

Rahagalala, P., Viljanen, H., Hottola, J. and . Hanski, I. (2009). Assemblages of dung beetles using cattle dung in Madagascar. African Entomology 17, 71-89.

Ronquist, F. and Heulsenbeck, J.P. (2003). MRBAYES 3: Bayesian phylogenetic inference under mixed models. Bioinformatics 19, 1572-1574.

Rutschmann, F. (2006). Molecular dating of phylogenetic trees: a brief review of current methods that estimate divergence times. Diversity and Distributions, 12, 35-48.

Scholtz, C.H. (2000). Evolution of flghtlessness in Scarabaeoidea (Insecta, Coleoptera). Mitteilungen aus dem Museum für Naturkunde Berlin, Deutsche Entomologische Zeitschrift 47, 5-28.

Scholtz, C.H. and Howden, H.F. (1987). A revision of the southern African genus Epirus Reiche (Coleoptera: Scarabaeidae: Scarabaeinae). Journal of the Entomological Society of southern Africa 50, 121-154.

Scholtz, C.H., Davis, A.L.V. and Kryger, U. (2009). Evolutionary Biology and Conservation of Dung Beetles. Pensoft Publishers, Bulgaria.

Simon, C., Frati, F., Beckenbach, A., Crespi, B., Liu, H., and Flook, P. (1994). Evolution, weighting, and phylogenetic utility of mitochondrial gene sequences and a compilation of conserved polymerase chain reaction primers. Annals of the Entomological Society of America 87, 651-701.

Smith, C.I. and Farrell, B.D. (2005). Range expansions in the flightless longhorn cactus beetles, Moneilema armatum, in response to Pleistocene climate changes. Molecular Ecology 14, 1025-1044.

Sole, C. L., Scholtz, C. H. and Bastos, A. D. S. (2005). Phylogeography of the Namib Desert dung beetles Scarabaeus (Pachysoma) MacLeay (Coleoptera: Scarabaeidae). Journal of Biogeography 32, 75-84. 
Sole, C.L. and Scholtz, C.H. (2010). Did dung beetles arise in Africa? A phylogenetic hypothesis based on five gene regions. Molecular Phylogenetics and Evolution 56, 631641.

Sorenson, M.D. and Franzosa, E.A. (2007). TreeRot, version 3. Boston University, Boston, MA.

Swofford, D.L. (2003). PAUP*: Phylogenetic Analysis Using Parsimony (and other methods) Versdion 4. Sinauer Associates, Sunderland, MA.

Vogler, A.P., DeSalle, R., Assmann, T., Knisley, C.B. and Schultz, T.D. (1993). Molecular population genetics of the endangered tiger beetle, Cicindela dorsalis (Coleoptera: Cicindelidae). Annals of the Entomological Society of America 86, 142-152.

Wahlberg, N. and Wheat, C.W. (2008). Genomic outposts serve the phylogenomic pioneers: Designing novel nuclear markers for genomic DNA extractions of Lepidoptera. Systematic Biology 57, 231-242.

Wild, A.L. and Maddison, D.R. (2008). Evaluating nuclear protein-coding genes for phylogenetic utility in beetles. Molecular Phylogenetics and Evolution 48, 877-891.

Winterton, S.L., Hardy, N.B. and Wiegman, B.M. (2010) On wings of lace: phylogeny and Bayesian divergence time estimates of Neuropterida (Insecta) based on morphological and molecular data. Systematic Entomology 35, 349-378.

Wirta, H. and Montreuil, O. (2008). Evolution of the Canthonini Longitarsi (Scarabaeidae) in Madagascar. Zoologica Scripta 37, 651-663. 